Article

\title{
Online Gamified Learning to Enhance Teachers' Competencies Using Classcraft
}

\author{
Szarmilaa Dewie Krishnan, Helmi Norman * and Melor Md Yunus
}

check for updates

Citation: Krishnan, S.D.; Norman, H.; Md Yunus, M. Online Gamified Learning to Enhance Teachers' Competencies Using Classcraft. Sustainability 2021, 13, 10817. https:// doi.org/10.3390/su131910817

Academic Editor: Eila Jeronen

Received: 24 July 2021

Accepted: 22 September 2021

Published: 29 September 2021

Publisher's Note: MDPI stays neutral with regard to jurisdictional claims in published maps and institutional affiliations.

Copyright: (c) 2021 by the authors. Licensee MDPI, Basel, Switzerland. This article is an open access article distributed under the terms and conditions of the Creative Commons Attribution (CC BY) license (https:/ / creativecommons.org/licenses/by/ $4.0 /)$.
Faculty of Education, Universiti Kebangsaan Malaysia, Bangi 43600, Malaysia; szarmilaa@gmail.com (S.D.K.); melor@ukm.edu.my (M.M.Y.)

* Correspondence: helmi.norman@ukm.edu.my; Tel.: +60-3892-13858

\begin{abstract}
Every English language teacher should be competent enough to serve as a model of reference for students. As stipulated by the Roadmap 2015-2025, Ministry of Education, Malaysia, teachers need a minimum CEFR Level C1 qualification to teach English language at all levels. This poses a need for teachers who have not achieved this minimum requirement to re-skill and upskill themselves to the minimum competency level. Past studies have indicated that online gamification techniques have increased teacher competency levels. However, there has been a lack of studies that have investigated teachers' language-teaching/learning competencies using online gamified learning. As such, this study aims to address this problem using experiential learning techniques on an online gamified platform, Classcraft. The online gamified learning module was developed using the Design and Development Research (DDR) methodology, and was conducted in the five-phase ADDIE Model (analysis, design, development, implementation, and evaluation). This paper seeks to brief the reader on the design and development process of this online gamified learning using Classcraft. The findings of the design phase were derived through the Fuzzy Delphi technique to acquire the experts' consensus on the content of the module, and the appropriate gamification elements which ought to be included in the development of the module. The findings of the development phase, as agreed by expert consensus, were used to develop the online gamified learning module. Thus, the findings portrayed the enhancement of the competencies of the English Language teachers who used this online gamified learning with the integration of Classcraft.
\end{abstract}

Keywords: online gamified learning; teachers' competencies; Classcraft; technology enhancedlanguage learning; English language

\section{Introduction}

Emerging technologies and explosions in digital information have caused numerous paradigm shifts in education and its systems. Kaarakainen vividly expressed that digitalisation has been advancing into education for a long time now, and even the idea of having a range of various digital tools and platforms has shifted a lot during the most recent couple of years, in which the pattern is going upwards [1,2]. Online learning has been employed in many greater training establishments to provide a deep and significant gaining of knowledge for rookies learning about technology [3,4]. This is where the online gamification platform becomes relevant to educators at large, as it focuses on teachers: more precisely, English language teachers.

The Malaysian Education Blueprint (MEB) 2013-2025 aspires for transformative education, as it requires teachers to obtain the CEFR C1 level, and to possess pedagogical competence and mastery of the English language [5]. Norman mentioned that learning occurs best in the flow and interaction between both learners and their environment, such that cognitively authentic rather that physically authentic learning happens [6]. For this reason, there is a need for all English language teachers to initiate their own learning [7]. This research aims to develop and design an online gamified learning environment for 
teachers to enhance their competency level nationwide, using Classcraft as a gamified platform. It also aims to cater to the best of the means in favouring the teachers in learning interestingly, as well as being in line with the national policy. The online gamification platform goes beyond flexibility in creating both challenging and entertaining tasks for learning [8].

This research was carried out using Classcraft as a fully online digitalised instructional gamified platform to enhance the English Language teachers' competency. Here, online gamified learning not only served as a background but also as instruction for teaching and learning to happen [9]. Furthermore, Classcraft was used as a tool for teaching and learning because Boettcher and Conrad said, in their research, that there is a demand for an online programme that has increased over the past decades, and it meets the demands of today's teachers [10]. Therefore, it is a way forward for policymakers and the relevant authorities to buy in to the idea of using an online gamified learning platform for professional development courses.

Infusing multiple technologies into one's learning is common in almost every field, and even more so in professional development courses simply because language teaching and learning has evolved to the point where even technology has superseded and enhanced traditional modes of instruction. In fact, language learning integrated with technology has become a prevalent routine [11]. Online learning is one of the technology pedagogies that has not let geographical constraints deter the desire to teach or study. The combination of teachers' efforts and technological advancements to improve the quality of education and learning has resulted in several advantages. Easy access to resources, adaptable space, study time and speed, and rapid feedback are just a few of the perks that make language learning possible, particularly for teachers during this epidemic. In addition, globalisation has created an environment in which learners no longer want to be place-bound [12]. Instead, they prefer a flexible, online learning environment that allows them to engage in their educational goals anywhere, anytime. It was further explained that online learners do not need to be time-bound, meaning that they do not have to struggle with specific days and times to attend class, as they have the flexibility to engage in learning when it fits their schedule [13]. In addition, they do not have to spend time driving or commuting to the class, so it provides the convenience for them to not have a large block of time to spend on upgrading themselves. Teachers who formerly relied on a textbook, a tape recorder, and a chalkboard are now efficient at presenting grammar with PowerPoint, listening to podcasts to practise listening skills, and extracting texts from the Internet to introduce listening skills, for instance [14]. Thus, online learning provides learners with flexible learning opportunities that suit their busy lifestyles, as well as the accessibility to connect with friends across the country and the world, especially with the existence of the pandemic [15].

Furthermore, teachers can create their own professional learning community (PLC) amongst the others in the country. Lindsay stated that online learners who are in geographically separate location can communicate and make connections with one another and others [16]. It is in this community of this era that they receive the opportunity to bring their experience into their discussion and make real life connections. This is what makes PLC possible.

This study also expects to show that online gamified learning provides opportunities for exciting and innovative experiences for teachers by engaging in the learning platform, as it employs experiential learning strategies [15]. Technologies have emerged as opportunities for learning, and to cultivate professional learning avenues $[17,18]$. They have expanded across time and space, which ultimately creates online communities of teachers which eventually work towards achieving the goals of PLCs. Teachers may, in fact, use this platform to enhance their topic and pedagogical content knowledge, as well as to change their teaching techniques. Online environment flexibility is the most significant element in facilitating teachers to access and share knowledge without any limitation of space and time. 
Thus, it is anticipated that the findings of this research will help the Ministry of Education to make the teaching profession favourable by pushing educators to higher accountable standards. By doing so, the Ministry of Education will be able to align its objectives with the aims and vision of the MEB. This online gamified learning is developed according to the recommendations submitted by Cambridge Assessment, and as an alternative to an existing initiative by the Ministry of Education [19]. The innovation of this online gamified learning module would enable the English language teachers to improve, experience and imbibe the content in their teaching in order for successful learning to take place. They are assured of improving in both their pedagogical and knowledge skills. Undoubtedly, the implication of this online gamified learning is far reaching, especially to the English language teachers in Malaysia.

As per Figueroa, the term "game" is widely acknowledged to signify the following situational components: a target that must be attained, an attempt to limit the rules that determine how to achieve the goal, a feedback system that provides information about progress toward the goal, and the fact that participation is voluntary [20]. Gamification is the practise of motivating people in non-game activities by using game design elements, game mechanics, and game thinking [21]. Gamification transforms the entire learning experience into a game. It combines gaming mechanics and gaming aspects with current learning courses and content in order to better inspire and engage learners. Achievement badges, points, leader boards, progress bars, and levels/quests are some examples of these mechanisms. Malmberg has also said that this includes instructional materials, learning goals, behaviours and attitudes [22].

\subsection{Gamification and Online Gamified Learning}

Gamification is one of the educational approaches and techniques that increase the motivation and engagement of learners [23]. Kapp, in his research, said that gamification is defined as "the use of game mechanics, aesthetics, and game reasoning to connect with people, motivate action, increase learning, and resolve issues" [24]. In other words, gamification uses elements, approaches and game thinking in a different context, as these are used in the learning process. Gamification is the incorporation of game features and game thinking into non-game activities [23]. Similarly, gamification is described as the use of game metaphors, features, and concepts in a learning environment that is clearly distinct from that of games [23]. Gamification increases the commitment and motivation to influence behavioural intention. Gamification is the act of incorporating gaming aspects into already existent things, in this context teaching and learning approaches [25].

The online gamified learning platform provides a sophisticated set of tools for the tracking of learners' engagement in course activities. Getting a quick look at how the learners progress gives the e-moderator much-needed information quickly, in split seconds. The online gamified learning platform can provide at-a-glance statistics about learner access, grades and discussion board participation. According to Boettcher and Conrad, monitoring learner's engagement and activities within such a platform is easy and useful [10].

Online gamified learning not only ensures student engagement in class but it may also give an alternative method of encouraging active involvement and interest in anything other than the academic requirements of a course. It should be used in conjunction with other well-researched engagement methods. The reason for this is because gamification permits us not only to develop a paradigm that encourages learners to attempt new things and not be terrified of failing, but also to engage learners in pleasant experiences for the goal of learning. Another significant advantage is the low production cost and the ability to make learning content more attractive or entertaining by including gaming elements [21]. A few of the most prominent learning applications and platforms online, such as Duolingo and Classcraft, have incorporated gamification into their services for years now. 


\subsection{Online Gamified Learning Using Classcraft}

Classcraft is a free web platform that allows instructors to develop quizzes that are utilised for a certain period of time in order to help students in the class and assess them individually or in groups, depending on their learning mode. According to its official website, it was created in 2015: "Launched in 2015, Classcraft is an award-winning, teacherfriendly gamification tool that is presently utilised in over 50,000 classrooms in seventy-five countries in eleven languages" [26]. Shawn Young was the initiator of Classcraft in January 2011. Since its launch, Classcraft has become very popular with educators worldwide, because it provides tools to transform behavior and classroom cultures. The initial version of the digital platform, which was extremely rudimentary, was designed for personal use only, but after three years, the regulations were changed so that more educators could use it. Classcraft is one of the gamification platforms that extends the existing course architecture with an adventure game layer. Learners in this adventure game learn by designing their own character, participating in a team, and eventually receiving experience points and prizes, depending on the lesson activities [21]. Nowadays, young people-predominantly adolescents - spend their time on digital games, making them a popular form of cultural interaction in our society. Thus, it is no wonder that digital games are the target of many educators, who use them as powerfully motivating digital environments [27].

In Classcraft, every player is represented by an avatar. In this game, the rules are simple and straightforward; so much so that a learner who plays this game can earn "Experience Points (XP)" by demonstrating positive behaviour in class. This will enable him/her to move up and gain special experiences. Nevertheless, if a learner "violates" the class regulations, he or she will lose "Health Points (HP)" - his or her life force in the game-and will eventually die in combat. For example, if a learner gains XP points, the additional abilities he or she gains will help both the learner and his or her team [28]. In contrast, if the learner loses HP points, he and the whole of his/her team will lose the fight, and therefore the game. In order to win, learners may have to work as a team. In ClassCraft, there are teams such as Mages, Warriors, or Healers for learners to assume in order to take part in the game. Interestingly, each group has its own set of traits and powers that are tailored to distinct types of learners [29]. When a learner joins a team, he or she can take on the role of a Warrior, Mage, or Healer, as each team includes at least one Warrior, Mage, and Healer; this allows them to assist each other to succeed in the game, because the learners are participating in the class activities created in the Classcraft platform [30]. The game duration and features are set by the game admin who uses this game mode, while learners who have their own account get to login to play the game. When learners login to their game, they get to manage their character and powers [31]. Furthermore, Classcraft enables the game admin — or Gamemaster-to have a global and individual view of the game's progress. In other words, the instructor or game master could see an individual learner's progress, a specific team's progress, or the progress of the entire class [32].

Learners gain experience points for excellent work and teamwork in Classcraft's system, but they suffer hit damage if they lose concentration or skip sessions. When learners respond throughout the game, they receive their findings collectively and in realtime, permitting facilitators to gain rapid insight into learners' levels of comprehension of a certain subject area. Learners, too, may level up and obtain powers which are unique to their character class, which they can use to aid and protect their teammates (or themselves), activating them live as events occur in the classroom. Hence, this tool is easily accessible if there is a good internet connection (the game master needs to give learners the code to be part of the platform). Indeed, Classcraft reflects the style of World of Warcraft [33]. 
Classcraft employs a series of role-playing game features, such as character creation, levels, quests, goal setting, and layered reward structures [34]. It is well-known and widely used by primary and secondary school level learners because of its range of mechanics, and several studies have demonstrated that these sorts of game mechanics may engage and help learners on their learning journey in a myriad of areas. Classcraft corresponds to the gamification of teaching by integrating roleplaying game features [35]. Learners in Classcraft have characters that they level up based on what they accomplish during the learning process, and this action enhances their interest, leading to more engaged learning. Classcraft has been shown in an extensive study to be a tool with tremendous possibilities for involving and engaging students in the EFL classroom [32].

Classcraft is an excellent example of gamification, which is the application of game concepts to non-game contexts, and is rapidly becoming a prominent trend in modern education. Thus, the benefits of Classcraft could be explained by its affiliation to this trend: it helps to motivate learners by creating the possibility of real risks and rewards, teaches them to act as a team, and makes learning fun by introducing an ecosystem of badges [36]. Forsberg stressed that it could bring more fun for the learner, and that it gives more and different stimulus to their learning process [2]. In fact, teachers are using gamified applications quite a lot, and are seeing the benefits in using them. Subsequently, learners will take the autonomy to upgrade their own learning in line with the Roadmap [7].

Many papers and works have indicated past studies, but the gap still persists in involving teachers as the sample in the use of gamification as an avenue to enhance their competencies. All of the past studies have used students and employers from all walks as the sample, but teachers-more precisely, English language teachers in Malaysia-have never been involved in any such study in relation to the issues discussed. Consequently, this could be a way forward in addressing the suggestion mentioned by Sukri and Yunus in their paper that future research may explore other key aspects of infusing learning in a way attracts the teachers [37]. Henceforth, this study aims to incorporate all the fundamentals of gamification, online gamified learning and Classcraft using English language teachers of CEFR B2 level in the determination of the development in them by obtaining CEFR level $\mathrm{C} 1$, as proposed in the national policy.

Thus, this study bridges the gap identified by creating online gamified learning to ascertain whether this is the way forward to continue supporting the teachers' requirement of obtaining and sustaining their minimum language proficiency level according to the Roadmap. It is also in line with Shift 1(Provide Equal Access to Quality Education of an International Standard), Shift 2 (Ensure Every Child is Proficient in Bahasa Malaysia and English Language and is Encouraged to Learn an Additional Language) and Shift 7 (Leverage ICT to Scale Up Quality Learning Across Malaysia), as stated in MEB 2013. The focus of this research is in tandem with the growth of online learning incorporating gamification in teacher training and teacher education. As a result, the goal of this article is to design and create an online gamified learning environment for English language teachers.

\subsection{Teachers' Competencies}

Competencies are explained as "the set of knowledge, skill, and experience required for the future, demonstrated in actions" [38]. The main dimensions of teachers' competency are skills, knowledge, and values, as were given in the Malaysian Teacher Standards model developed in 2009. Skills are associated with the capacity to perform physical tasks, knowledge is associated with cognitive domain information, and values are related to qualitative qualities such as personal characteristics, attributes, features, and excellent task or activity execution [39]. Teachers' professional competence denotes that they are professional and possess the personal qualities necessary for effective teaching. When teachers are professionally competent, they perform at a high level of teacher communication and using diverse teaching methods, continuously producing outstanding outcomes in the training and education of pupils. It was noted that professional competence makes teachers become 
individuals who use creative ways to teach; they are prone to use innovative teaching styles and tools, and most importantly they adapt themselves to transform the educational environment. When teachers develop professionally, they are elevated socio-economically, leading to the spiritual development of society. The professional competence of teachers, therefore, can be developed in many ways, and one of these is through the usage of educational technologies [39]. As a result, there is a need to inspire and decide what is best for teachers in order to advance them professionally. Therefore, this paper concentrated on showcasing an online gamified platform for teachers and their professional growth in competency, which promotes the creation of creative uniqueness, susceptibility to the emergence of educational innovations, and the capacity to deal with the current educational environment. As a result, the focus of this study will solely be on the system that has been used to improve teachers' knowledge and skills.

\section{Methods and Data Collection}

In order to achieve its aims, this study employs Design and Development Research (DDR) design by Richey and Klein [40]. For evolving product and tools, DDR is a one-of-a-kind, comprehensive, and systematic research approach. Based on Ritchey, in adapting the design study of type 1, the construction will be in accordance with Model ISD (Instructional Design) as an ADDIE model, namely (i) analysis, (ii) design, (iii) development, (iv) implementation, and (v) evaluation. However, as far as this paper is concerned, only in the design and development phase will focal details be shared. The Fuzzy Delphi Method (FDM) was used in the design phase to obtain opinions from the experts as a procedure to ascertain the consensual views of the experts on the design of the module. The FDM was carried out by distributing questionnaires to the 12 experts. A Likert scale, chosen by the experts, was converted to a fuzzy scale by the use of fuzzy numbering. In this study, the questionnaires were distributed to the experts in order to determine their consensus on the 5-point fuzzy scale. After this, the data from the 12 experts were analysed using fuzzy analysis in Microsoft Excel's preformatted Excel software to obtain the value of the instrument which would determine the development of the online gamified learning in Classcraft. This is the third phase of this study, which is the development stage.

In the first phase, this study collected data of the needs analysis found in the study. As guided by the ADDIE model, the requirements analysis phase to identify the problem to be solved in the study was conducted thoroughly, and it used a variety of methods, as appropriate. The results of each of the findings and recommendations obtained through the analysis phase were then used to implement phase 2 and phase 3 of the design and development phase. The identification of the issues was the objective to be achieved in the first phase of the study. The analysis of the findings in this phase involves a survey questionnaire for English language teachers involved in obtaining views of their perception on the needs of developing an online gamified learning to enhance teachers' professional competencies. As a result, the need analysis obtained from the teachers showed that most of the respondents were optimistic and positive about the use of technology in their daily lives, especially in the aspect of learning. In addition, the findings of this phase are intended to provide guidance on the positive attitude of the respondents to the form of survey in developing online games. Hence, they are being supportive, with a high tendency towards technology and its design; the results of the analysis in this phase give a good justification of the need to develop an online gamified learning module in order for the English language teachers to enhance their professional competencies. 
This provided evidence of the need to develop online gamified learning. The analysis of the literature was evident and suitable for the development of this online gamified learning. After the first phase of the requirement analysis phase was completed, the next phase was the second phase of the study: design. The findings of the needs analysis phase are important as a guide for the design process of online gamified learning. The design phase is an important and critical phase in the development of teaching material or modules. The principle in the study design and the development of teaching and learning materials is related to three main points: (1) learning content-structure and order; (2) strategy-adapted instruction; and (3) the use of media and delivery systems. In the next phase, the research was aimed at the development of online gamified learning [41]. This phase involved the construction of the online gamified learning proposed in the design phase. During this phase, too, the needs analysis that was carried out was also taken into consideration. The findings of the second phase of the design phase of the study were taken into account, and served as the primary basis for the purpose of development. A method of constructing materials in the development of online education studies in which a prototype is a product that is very similar to the final product is a high-fidelity prototype. This process is an important process which allows developers to specify their design and receive feedback. This stage or phase of the development process allowed the researchers to examine aspects of usability (usability), interfaces (interfaces) and issues related to product development. The prototype was developed based on Classcraft. This platform was chosen to promote online learning which is available for free and can be accessed by anyone. In this development phase, elements with the experts' consensus on the design phase were literally transformed, as well as being applied into Classcraft. In the implementation phase a pilot study was executed, and finally the fifth phase was the assessment phase, in which significant results were obtained through a survey conducted amongst the 100 teachers of B2 level. Most of them improved to C1 upon taking the final assessment, and a handful accomplished a remarkable level of C2. Thus, the findings markedly showed how the online gamified learning had enhanced the professional competencies of English Language teachers.

\subsection{Participants}

The participants were 100 English language teachers of CEFR level B2 from the southern, central and northern regions of Malaysia. The participants of the study consisted of 88 female teachers and 12 male teachers selected nationwide, adhering to purposive sampling. There were a variety of ages, ranging from the youngest, at 23 , to the oldest, at 58 years old. As for the ICT facilities available at their home, the largest number of 94 percent of the teachers used a laptop, and 91 percent of them used smart phones. About 27 and 26 percentage of the teachers still used mobile phone and tablets, while only 23 percent owned desktop PC at home.

\subsection{Instrument}

In this research, a Fuzzy Delphi Instrument was adhered to in the outlining of the content for the module. The experts' intervention in the determination of the appropriateness of the content was then deliberated. Therefore, it was geared towards seeking experts' content knowledge in the formation of the nucleus of the module. Classcraft was used as the platform to develop the online gamified learning module. Upon obtaining feedback from the needs analysis on the requirement and necessity of the teachers, the module matured to its fullest evolvement. A group of 12 experts had a discussion in order to obtaining their view on the appropriate elements to be incorporated into the format of Classcraft, which was incorporated in the development. The implementation of the discussion involved five experts from the English Language Teaching Centre (ELTC). The experts were knowledgeable, with years of experience in the development of modules for the English language teaching (ELT) area. The experts' consensus via the Fuzzy Delphi technique furnished the study with a profound guide to design online gamified learning 
in Classcraft. The agreed-upon elements were then included in the development of the gamified learning. The proposed elements were well received, with a high consensual value of among the experts involved upon being analysed through SPSS Version 22.0. Therefore, all of the agreed items or elements, such as the content, objectives, elements of gamification and other elements of gamification were taken into account, in accordance with the development of the online gamified learning in Classcraft. The content sculpted by these experts is relevant to the problem of the statement stated in the previous chapters. It consists of 5 levels, and thus 5 units comprising various tasks in the form of quests in Classcraft. It kicks off with Vocabulary, and gradually moves on to Reading and Grammar to culminate the learning process. The ultimate focus of each level is the elevation of the teachers to a higher level in the Common European Framework of Reference (CEFR) to enhance their professional competencies. It ends with a final assessment derived from the Oxford Assessment Test to mark their achievement upon completing the interventions in the form of quests and activities functioning as content.

\subsection{Data Collection and Analysis}

The content was then finalised by the experts, and the questionnaire was developed in accordance with the Fuzzy Delphi Method (FDM). Based on the outcome from the needs analysis that was conducted, the Fuzzy Delphi instrument was then developed in 4 constructs shown in the Table 1 below.

Table 1. Constructs.

\begin{tabular}{cc}
\hline Constructs Developed in Accordance with Recommendation Derived from Needs Analysis \\
\hline Part A & Demography \\
Part B & Objectives \\
Part C & Content \\
Part D & Gamification \\
\hline
\end{tabular}

Hence, the design phase became the foundation for the development of the next phase that will be produced in accordance with the DDR study. All of the items proposed were well received by selected experts from various expertise. Thus, the elements agreed upon will be complied according to their suitability and used dynamically as well as flexibly during the construction of the module in the next phase.

In this phase, the agreed-upon items were implemented in the development of online gamified learning to enhance English Language teachers' professional competencies. The module was built on an online gamified platform called Classcraft.

In the development of this module, all of the agreed-upon elements that were suggested by experts to develop the module were used. Based on the agreed-upon elements, the module was developed in 5 units with quests to complete, as mentioned earlier. In Classcraft, the tasks are called as "quests", and thus each level comprises several quests pertaining to the agreed-upon focus/skills. The basis for the construction of this module is to aid teachers to improve their reading skill, with this being the most difficult component to score good grades in according to the results received in the Malaysian University Entrance Test (MUET) [42]. Thus, the proposed platform, Classcraft, aims to cater to the needs of teachers to unpack the integrity requirement of reading skill which has been agreed upon by the panel of experts in laying the appropriate framework of content and assessment. 
In addition, the agreed-upon gamification elements were also incorporated in the development of the module. Table 2 below shows the details of the agreed-upon items, as indicated by the panel of experts.

Table 2. Agreed-upon elements of gamification.

\begin{tabular}{|c|c|}
\hline Elements & Agreed Items \\
\hline Basic multimedia elements & $\begin{array}{c}\text { Font size: } 14 \\
\text { 2D animation concept } \\
\text { Narrated video } \\
\text { Levels } \\
\text { Performance graph }\end{array}$ \\
\hline Gamification element & Quest, levels, performance graph, avatars, reporting \\
\hline Achievement and rewards & Points, Certificates \\
\hline Assessment & Discussion and Quiz \\
\hline Platform implementation & Online (Classcraft) \\
\hline
\end{tabular}

Relying on the consensus that the experts reached during the design phase, appropriate elements were utilised in the development phase to produce the Online Gamified Learning module. The selected elements, content and assessment are the outcome derived from the consensual agreement of the panel experts. The board of developers comprised 5 lecturers from the Ministry of Education, Malaysia, who were qualified and well-trained module builders, with backgrounds as follows: curriculum, technology, educational management, assessment, and the pedagogical field.

These 5 lecturers, with more than 15 years of experience, developed the quests and activities based on the agreed-upon items in Classcraft. The items approved by the experts were expanded in the development of the comprehension questions gearing to the activity as the final task. The module writers worked on reading comprehension, as requested in the needs analysis phase.

The design of the game is described in the form of a flow chart, navigation pane and storyboard engulfing the entire module. In this case, the pattern of the design is very crucial in the illustration of the prototype and the flow of the module. The flowchart records the pathway that is being sailed through by the player enhancing their professional competencies. It dictates the design of the game being explored. After this, the navigational guide depicts the pane that is being utilised throughout the game. The storyboard then reveals the process of the game design that is being composed upon the consensus of experts. These criteria facilitate the design of the game towards enhancing teachers' professional competencies.

The flowchart documents the process of the module, which makes it an essential part of research. It is depicted to aid the reader in grasping the game concept, and to offer a brief overview of the Classcraft built. The visualisation shows the sequence of the game being played, as illustrated in Figure 1. 


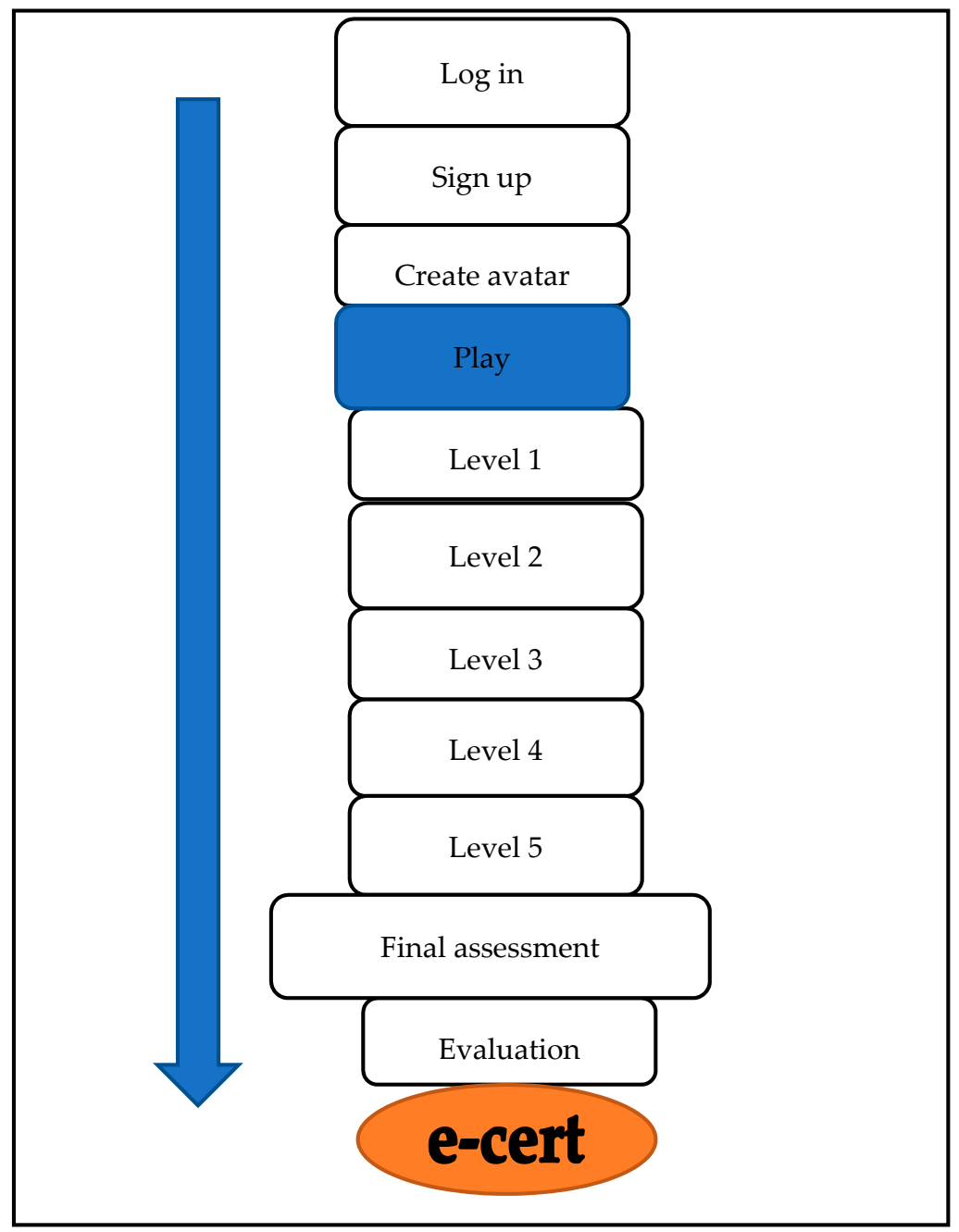

Figure 1. Flowchart of the game.

The platform called Classcraft is an existing online platform which allows built-in content. Therefore, the process of designing is confined to accessible features, but it permits the formation of content which consists of important components, such as the game home icon, dashboard, quests, and messaging. The graphical user interface allows effective access to the page. The crux of the gamification element is exhibited in the icons played in Classcraft.

Figure 2 portrays the feature icons available in Classcraft. An avatar is a profile character that empowers learners with personalized characters and special real-life effects. The player can customize how the Guardian, Mage, or Healer looks and feels in the game. The Health Points or HP is the life energy form of reward, and it should not drop to 0 . AP is the Action Points; the player ought to use their power to obtain the reward. The Experience Points (XP) measure the progress. The more XP is gained, the more one can level up and get cool new powers. Gold Pieces (GP) are the bonus score that will be awarded for special performances being exhibited. The reward system is to provide a higher impact on the players, as agreed by the panel of experts. 


\begin{tabular}{|c|c|c|}
\hline \multicolumn{2}{|c|}{ Other Design } & Description \\
\hline & & $\begin{array}{l}\text { Avatar - this feature allows } \\
\text { learners to personalise their } \\
\text { character in playing the game }\end{array}$ \\
\hline \multicolumn{2}{|c|}{ Rewards } & \multirow{5}{*}{$\begin{array}{c}\text { HP-Health Point } \\
\text { AP-Action Point } \\
\text { XP-Experience Point } \\
\text { GP-Gold Pieces }\end{array}$} \\
\hline HP & 30 & \\
\hline AP & 50 & \\
\hline$X P$ & 540 & \\
\hline GP & 550 & \\
\hline
\end{tabular}

Figure 2. The Icons in Classcraft.

The storyboard was developed to facilitate the development of the content, graphics, and animation. This storyboard serves as the main guide and reference in the development process. Therefore, the storyboard in Figure 3 denotes a significant step in the facilitation of the development of the Online Gamified Learning module. Figure 4 demonstrates the flow of the development process, in which the module is designed and developed in accordance with the consensual agreement of the experts.

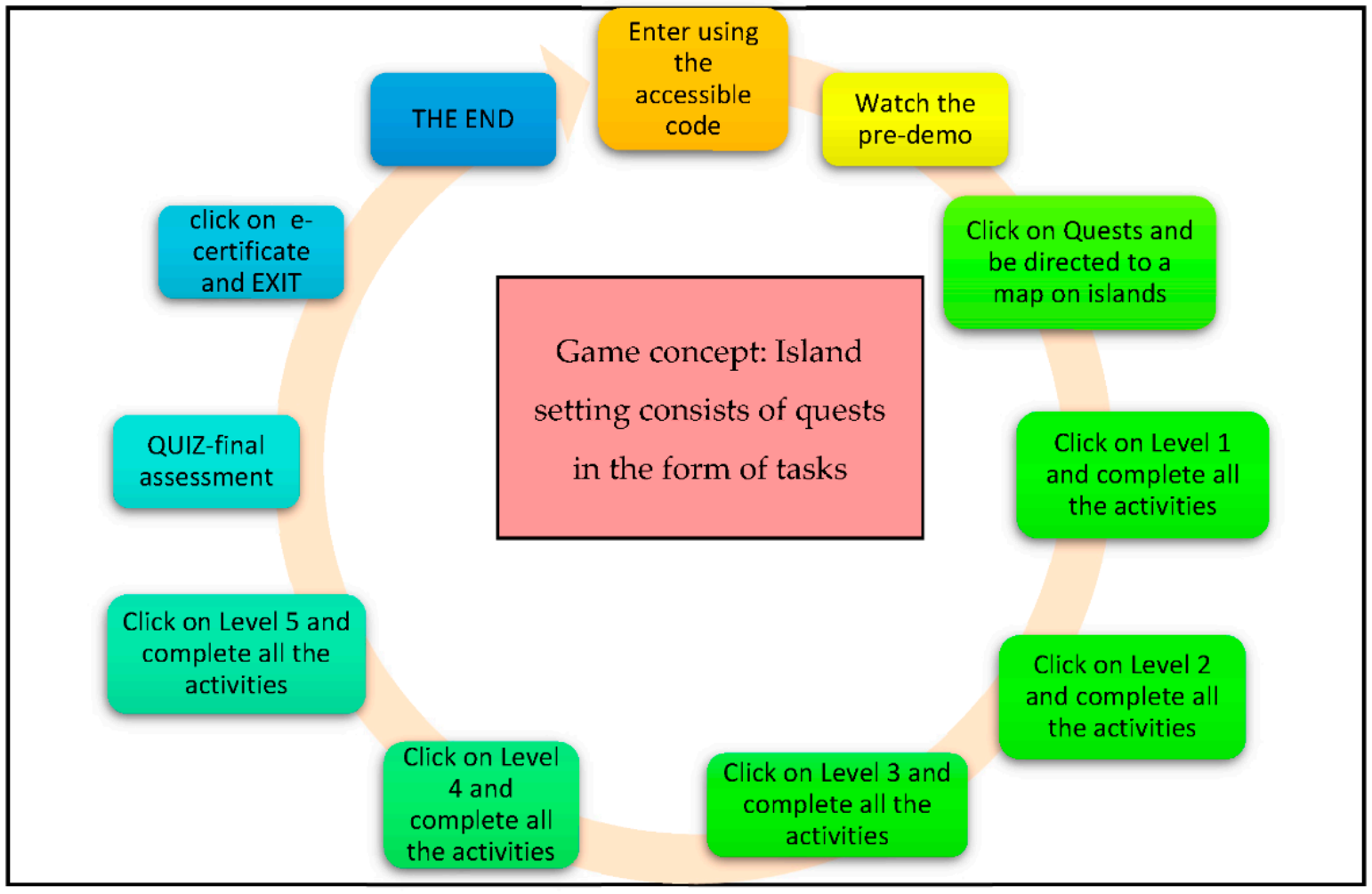

Figure 3. Storyboard. 


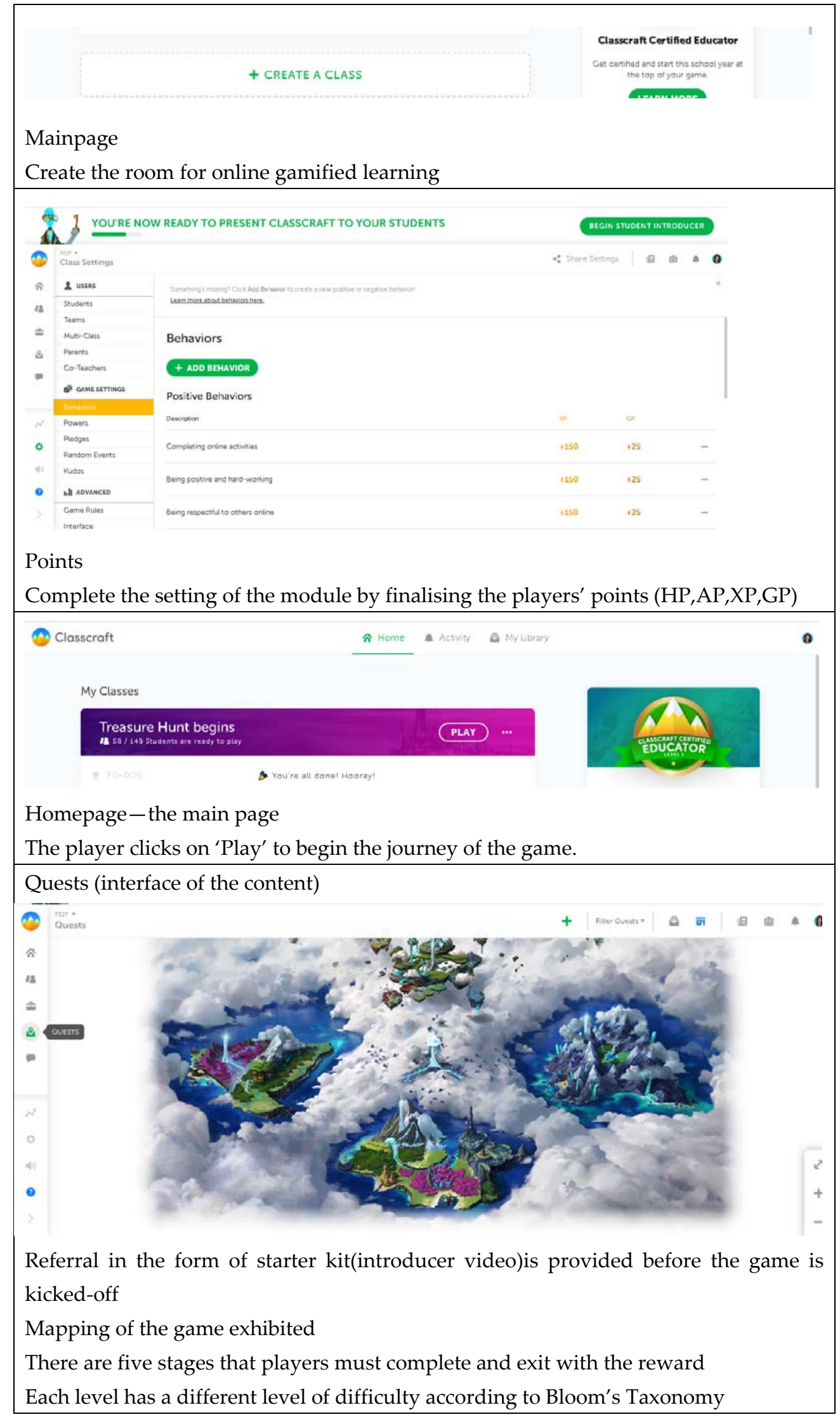

Figure 4. Cont. 


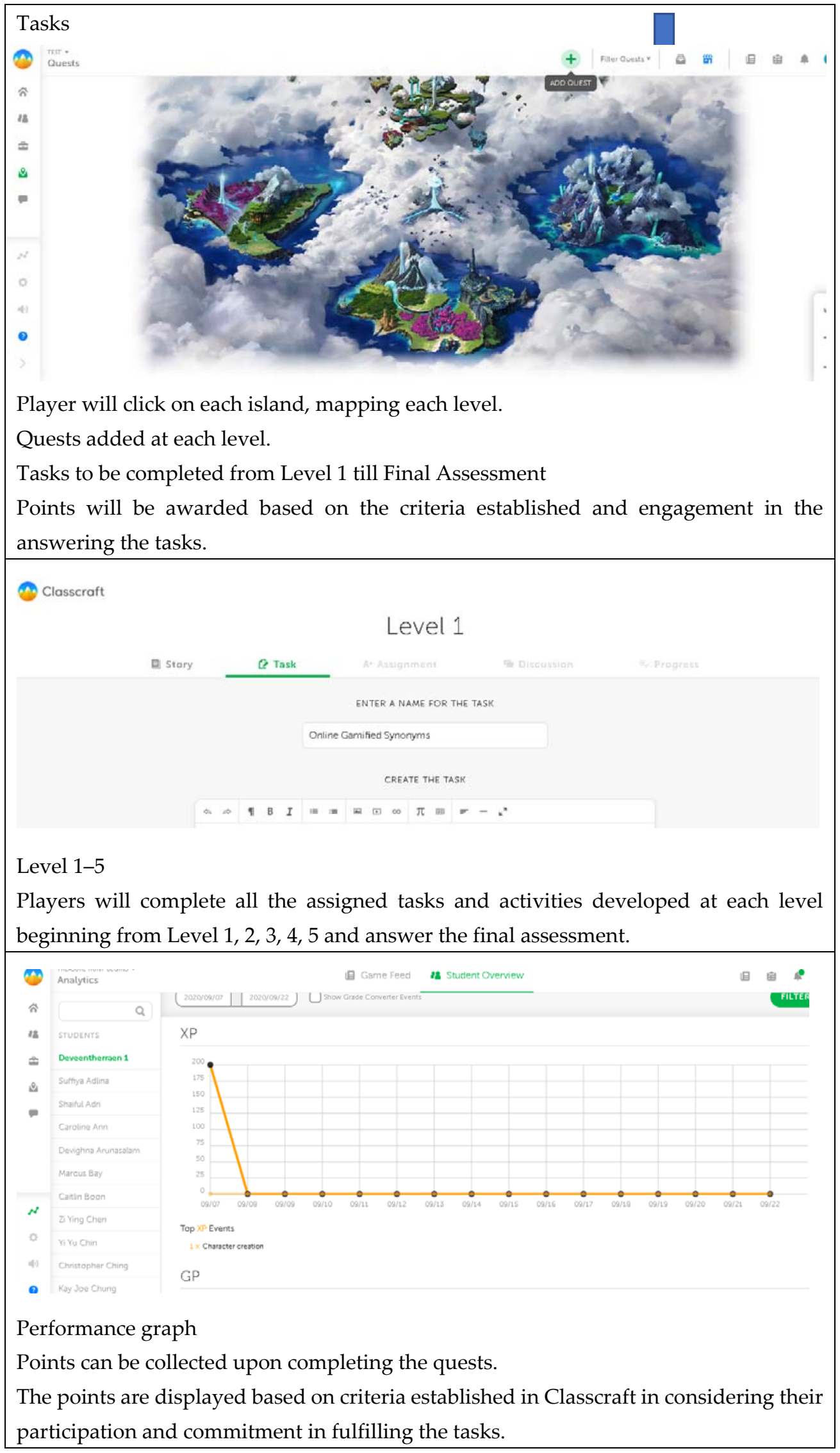

Figure 4. Development of the storyboard for online gamified learning. 
The storyboard is based on the construction developed by the experts of various expertise. The description in the table below reports the development of the storyboard as constructed by the experts. The built-in platform in Classcraft aids as a sequential guide in the development of the module as depicted in Figure 4.

As depicted in the figure above, the storyboard development was crafted after considering and analysing all of the agreed-upon elements, and with the consent of the module writers, who worked tirelessly in the construction of this module. The phases of the quests are adhered to until the final assessment is met in the determination of the final output. The players can then exit the game by obtaining the e-certificates stored in it for them.

Hence, the data obtained though the Delphi technique is then implemented and included for the next stage, which would show the outcome of this design after being analysed and crafted in Classcraft.

\section{Results}

Based on the results obtained from the Fuzzy Delphi technique in the design phase, the outcome was projected in the development phase. Upon conferring with experts on the development of the module, the module was then developed as illustrated below.

Figure 5 depicts the illustration of the online gamified learning in Classcraft, where the quests are scaffolded in five islands. The players, in the form of a selected avatar, would have to travel from one island to another, completing the tasks and activities assigned at each level.

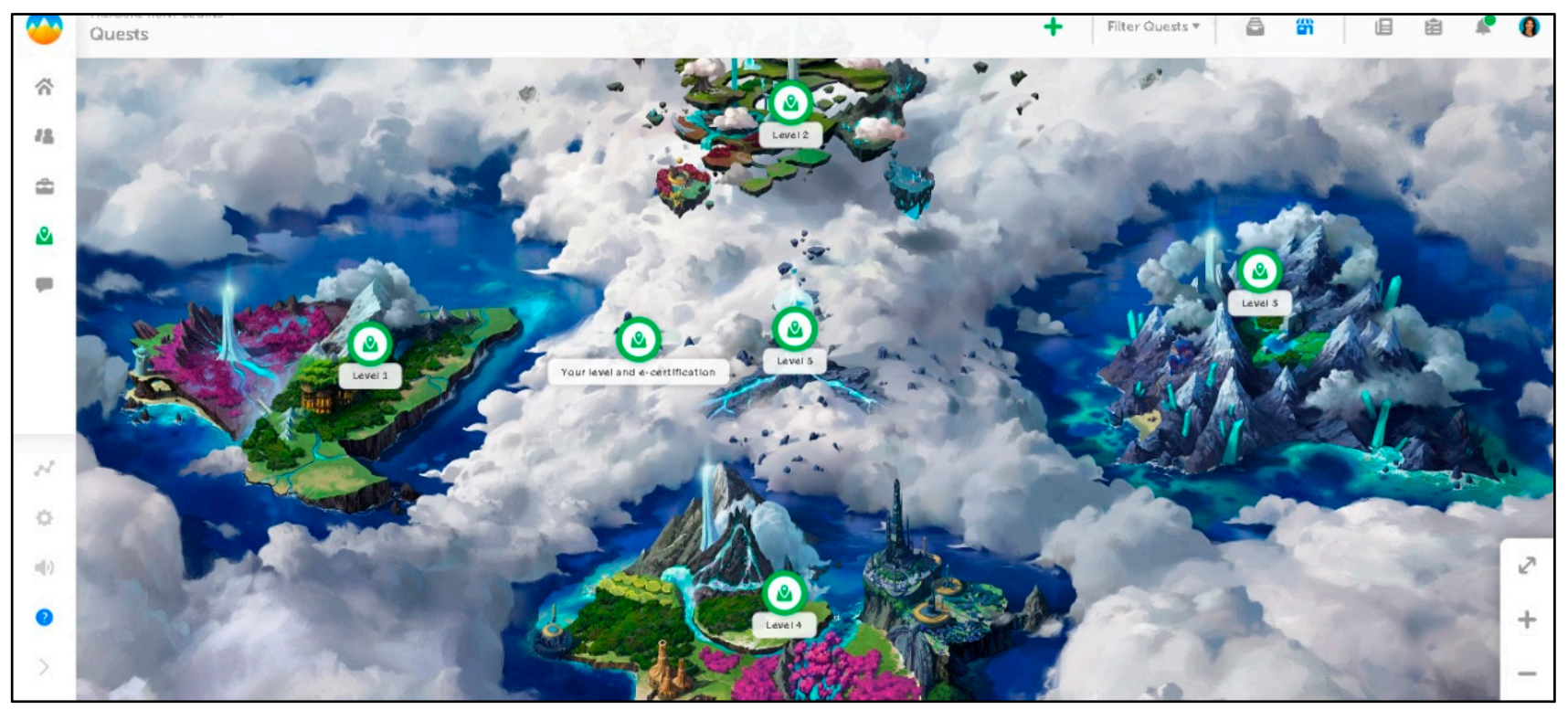

Figure 5. Mapping of the levels (Levels 1-5 and the Final Assessment).

There are four to five tasks allocated which would end with the completion of the activities. The task on reading skill and focusing on predicting outcomes was laid by the experts in the previous phase. The players have to read the story and predict the outcome. The responses are then posted in the discussion trait to be chatted about with the other players. Figure 6 shows the developed tasks in an island. 


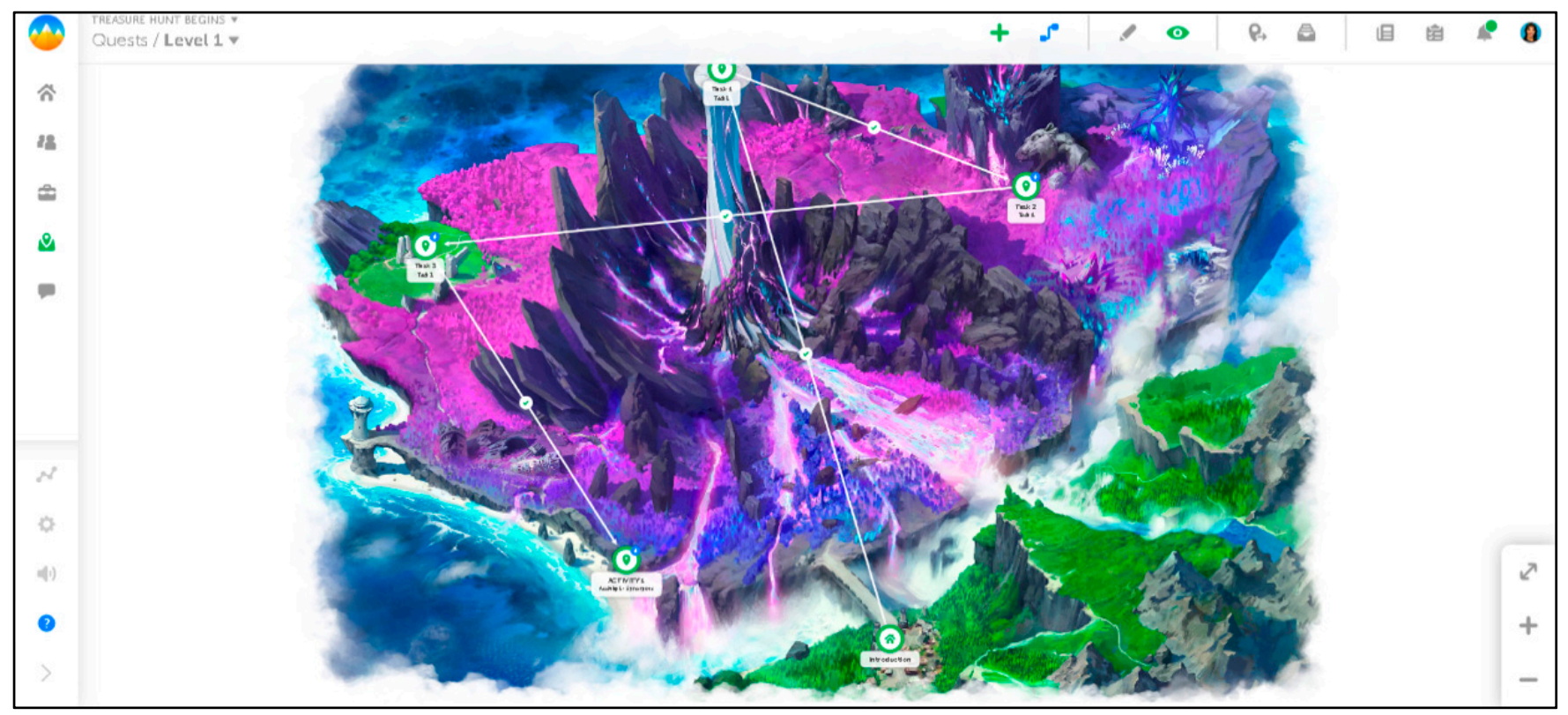

Figure 6. Level 1 and its tasks.

All of the tasks were developed based on reading comprehension skills, where the players' knowledge and skills are tested whilst progressing from a level to another. Figure 7 describes one of the outcomes of the task designed and developed. A similar outcome takes place in all of the other levels, respectively.

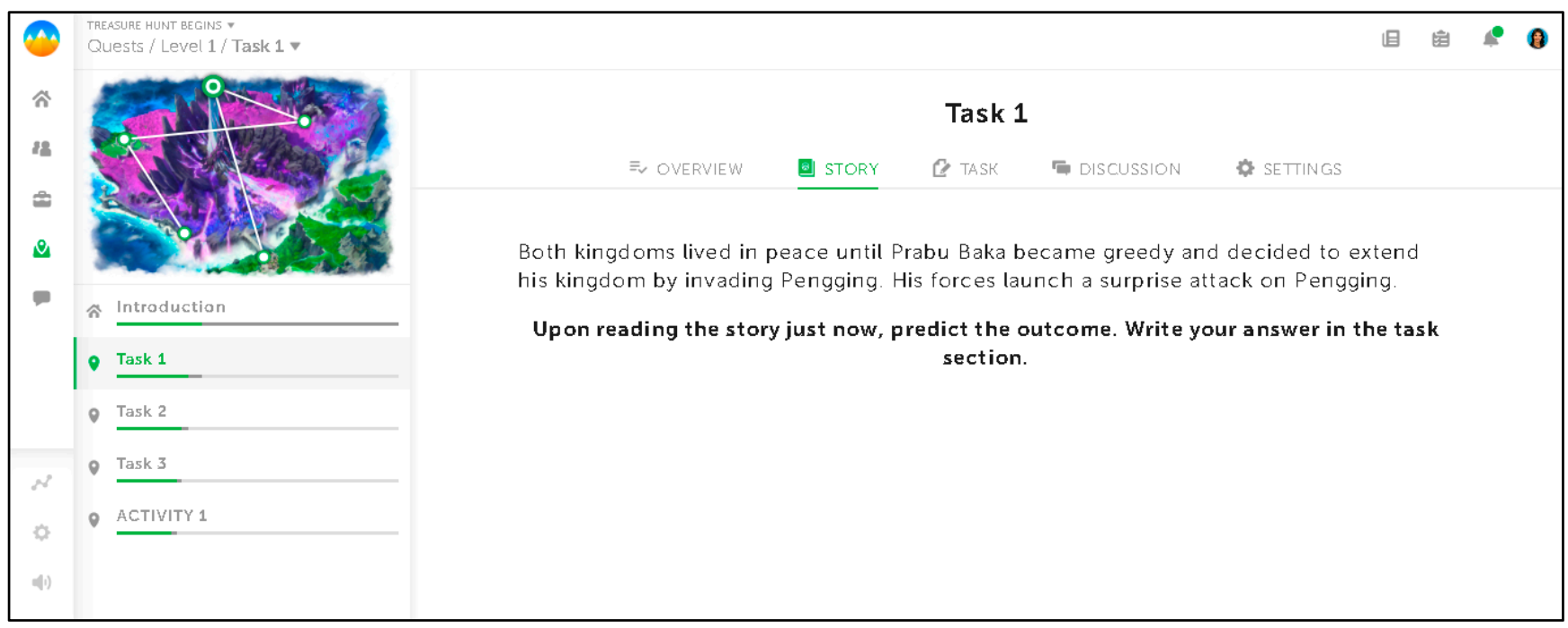

Figure 7. Sample task and its description.

In completing the tasks of a level, the player would also attempt the activities developed as the culmination of each level. The activities would be the final quest before progressing to the next island. The designed activities are online gamified synonyms, online crossword puzzles, online inferencing, the gamified prediction of an outcome in Plotagon, and an online quiz. Figure 8 resembles one of the activities captured. 


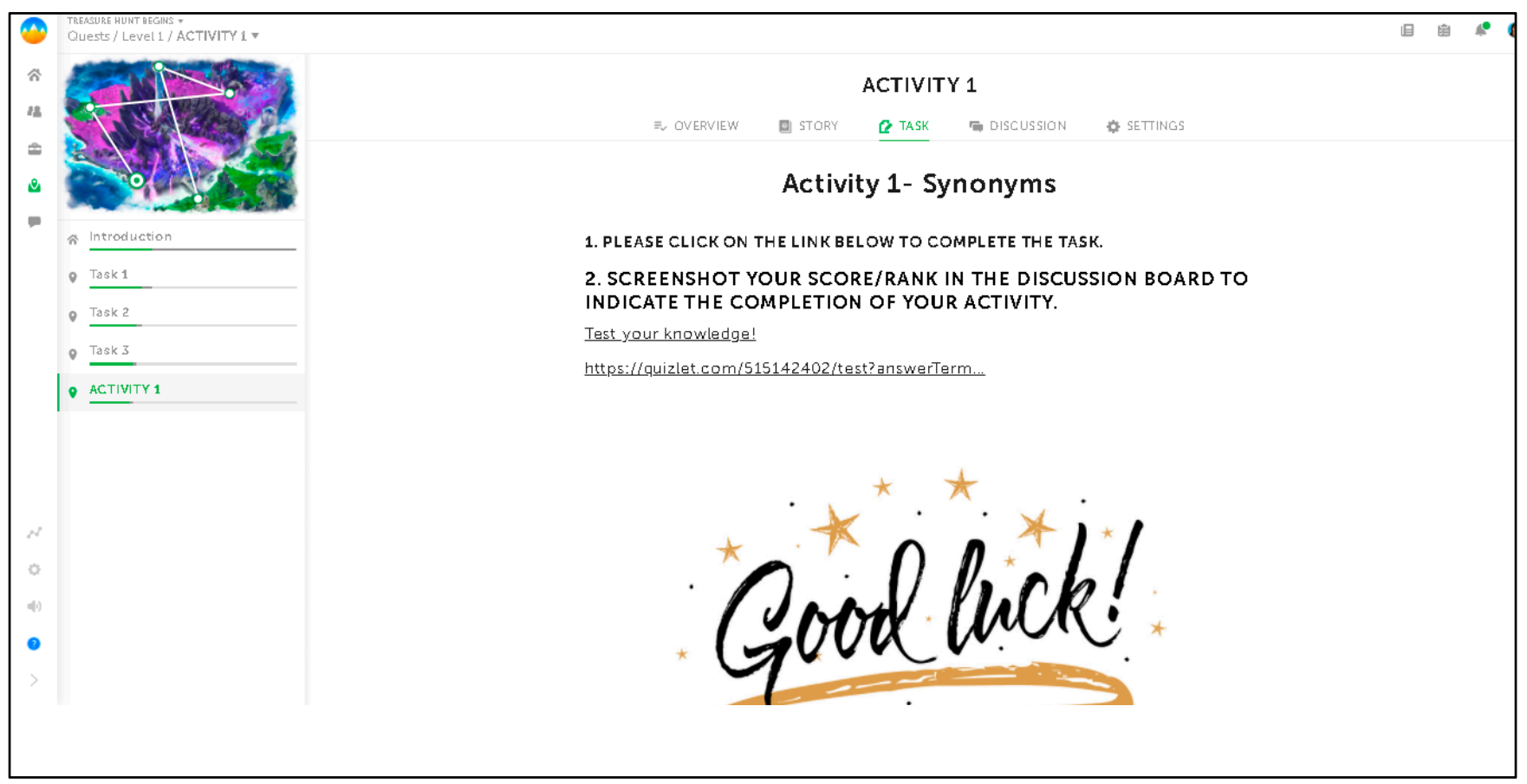

Figure 8. Sample activity.

Finally, the player is notified of the completion of the online gamified learning. The illustrations indicate the treasure found as part of the avatar's quest to find the hidden treasure by completing all the tasks and activities. Hence, a picture-as shown in Figure 9is placed to demonstrate their accomplishment.

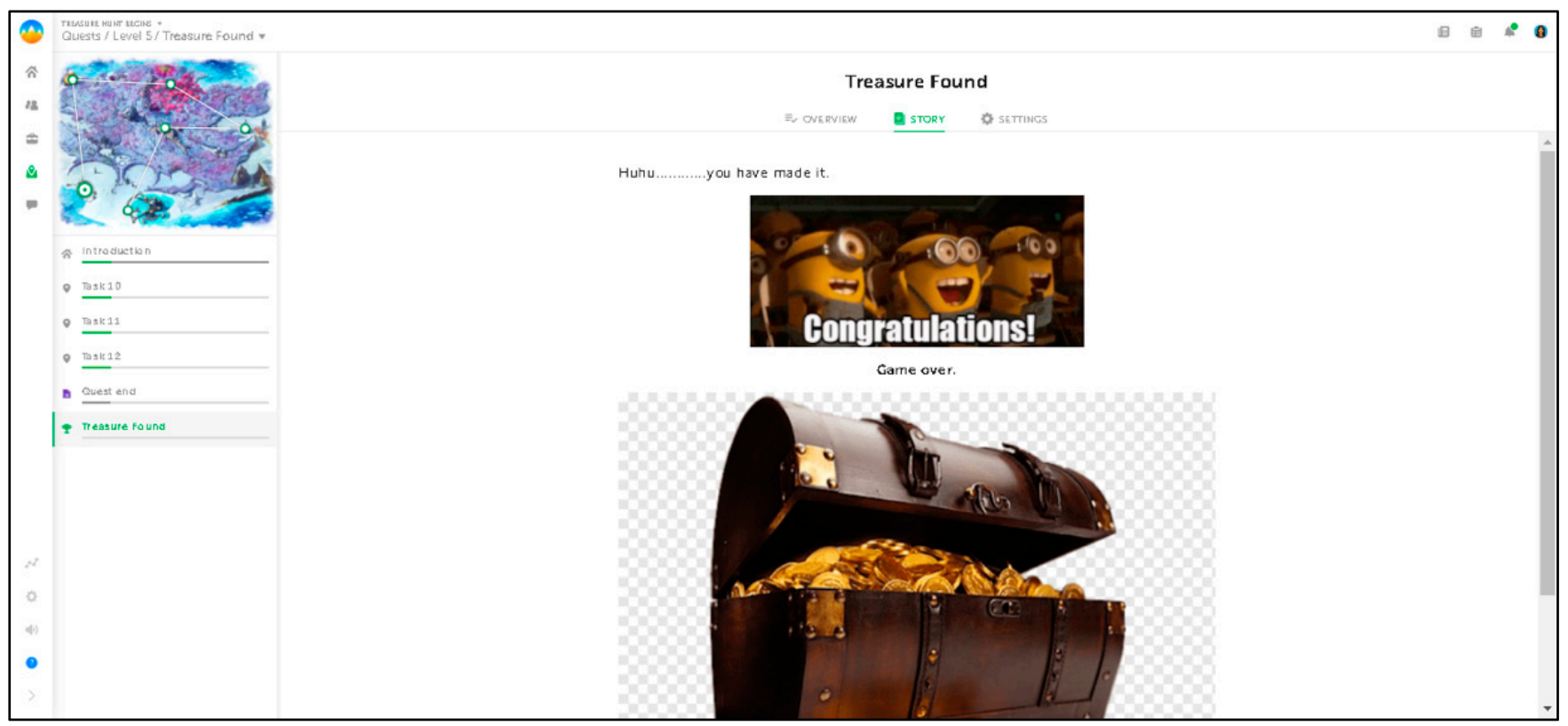

Figure 9. Completion of Level 5.

The final stage was designed and developed to assess their progress and the knowledge learnt and imbibed throughout the levels. The players answered an online assessment comprising 40 questions, and the results are in accordance with CEFR to exhibit the outcome of the module. All of the players managed to obtain the minimum C1 level in the final assessment. More precisely, $73 \%$ obtained C1 in the assessment conducted. Subsequently, 
$27 \%$ achieved the highest score, C2. Figure 10 illustrates the showcase of the final output of the development phase.

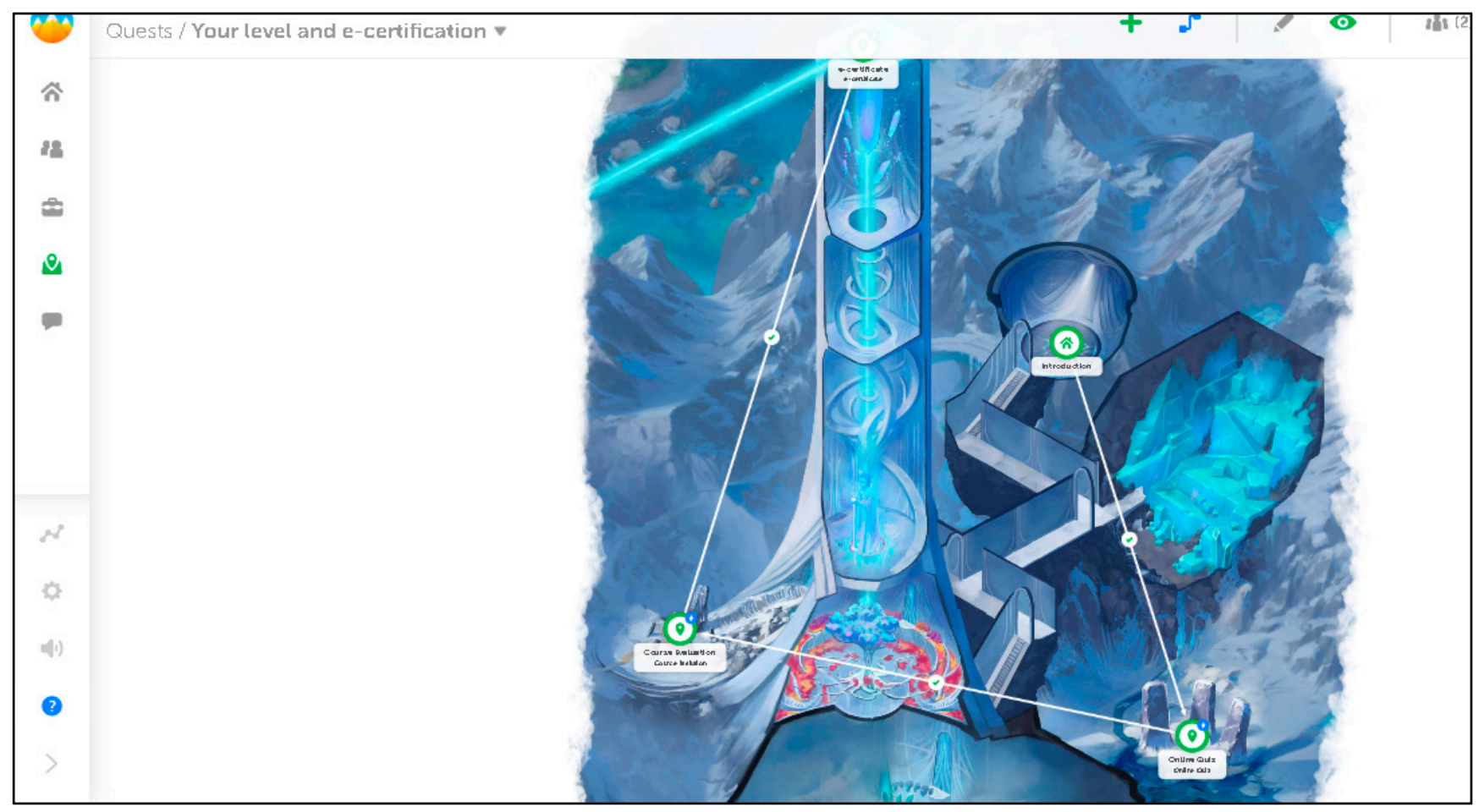

Figure 10. Final Assessment and e-certification.

The online gamified learning comes to an end by obtaining feedback from the players on the effectiveness of the online gamified learning, as displayed in Figure 11.

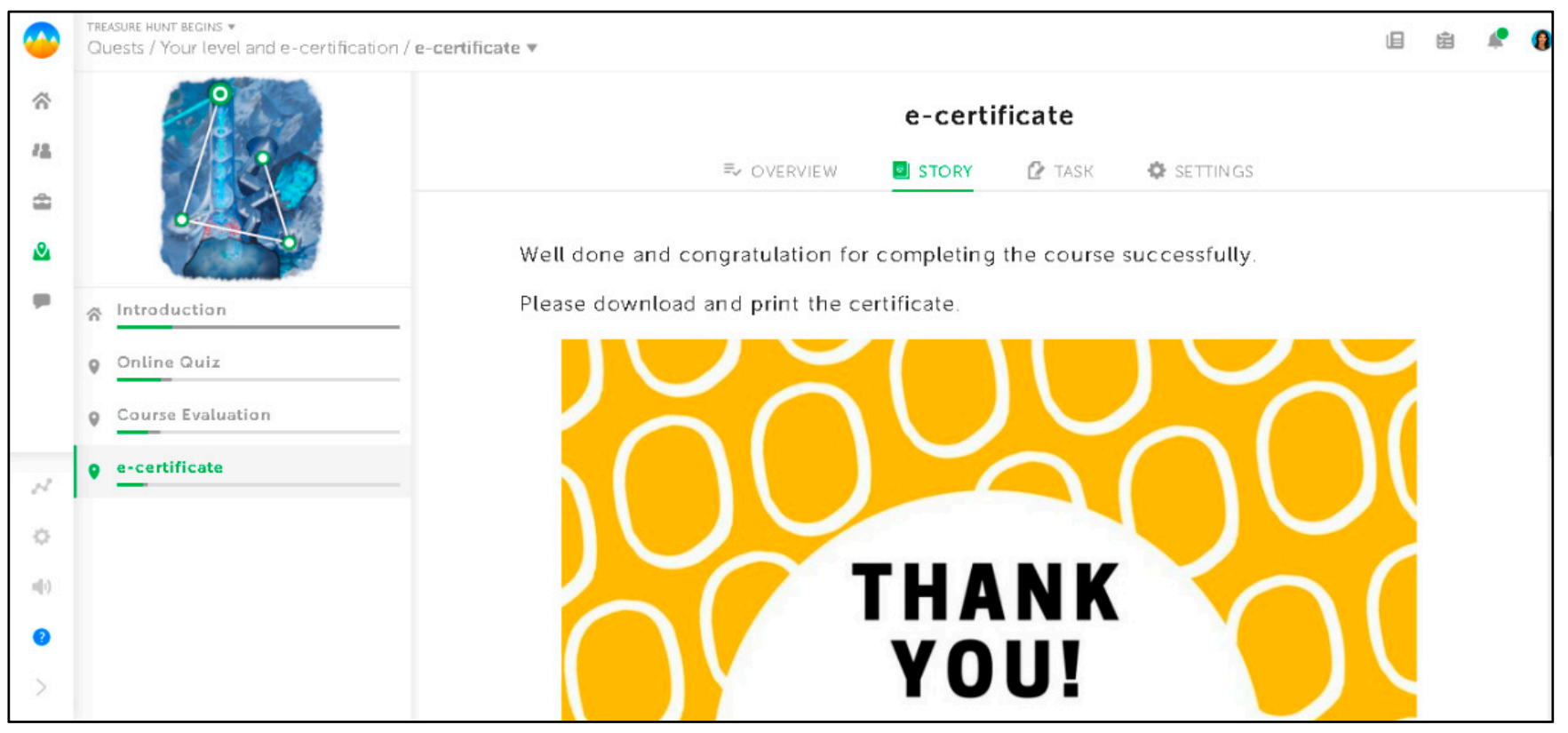

Figure 11. Game over.

So as to acknowledge and certify their achievement, the players receive an e-certificate, as showcased in Figure 12. 


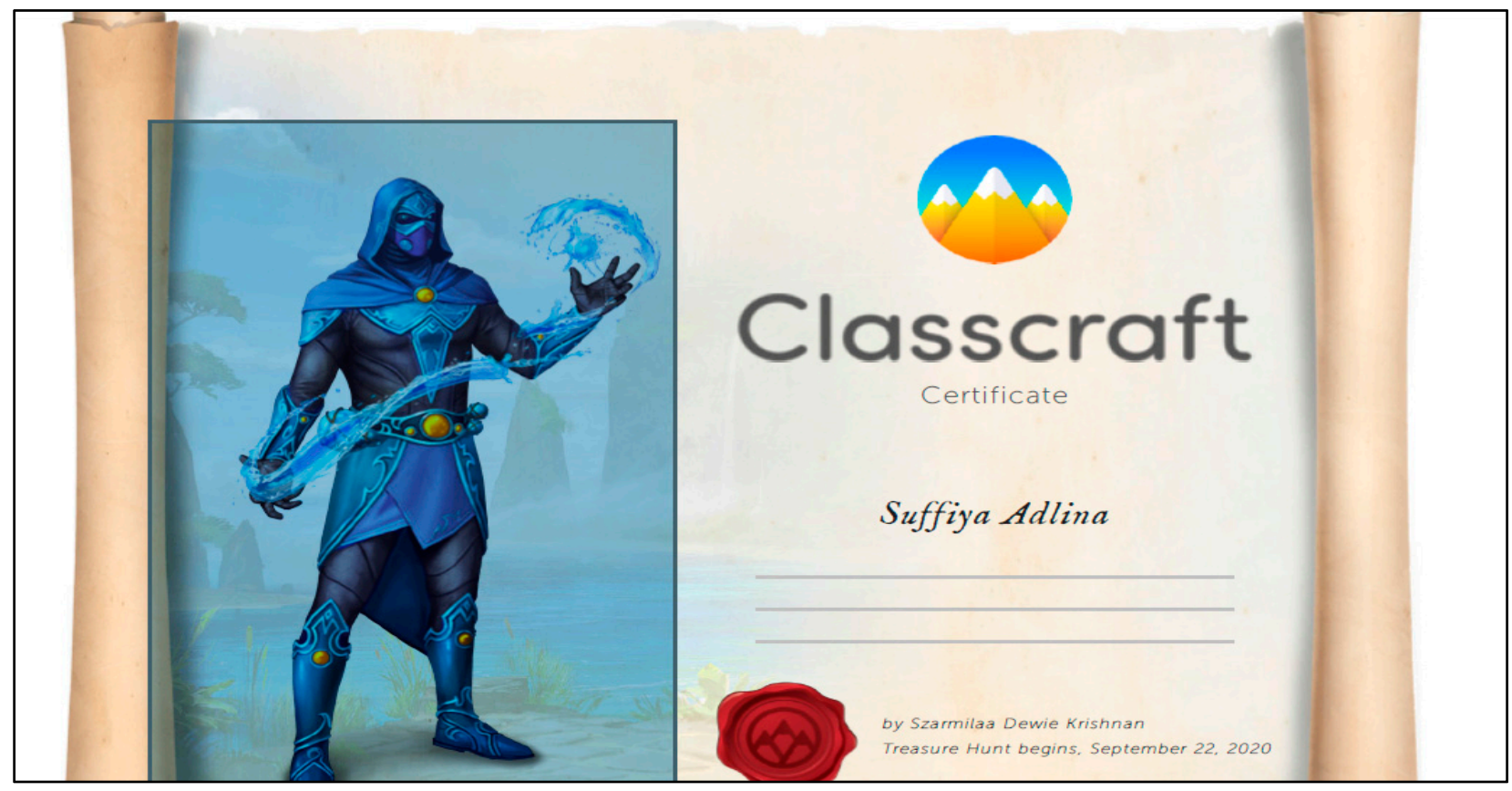

Figure 12. E-certificate.

In this development phase, elements with the experts' agreement and consensus on the design phase were literally transformed and applied into Classcraft. The evidence derived from the formative assessment resulted in the effectiveness of this online gamified learning module.

\section{Discussion}

At the design phase of this study, all of the elements proposed based on the literature review were then well-received by the panel of selected experts consisting of field experts in accordance with the requirements of this study, as mentioned above. In addition, Gunter also made a similar notable point as the required featured elements [43]. The experts agreed that all of the constructs appearing in the Online Gamified Learning components were very appropriately being used in the instruments in gearing to the development of Online Gamified Learning. Meanwhile, educational and technological experts explicated highly recommendable opinions on the appropriate gamification and multimedia elements to be adapted in the online game, which was then developed. Therefore, the agreed-upon elements were then selected appropriately and used dynamically and flexibly during the construction of the games in the next phase. These findings can be attributed to the study of Syed and Hussin on the distinctive educational elements intended to ensure that learners discover progressively when playing them [44].

As asserted by de Lope et al. (2017), before designing storyboards and game challenges, appropriate gamification elements need to be determined. These features include the font size, 2D animation, voice over, and narrated video. In line with this study, Sauvé also indicated a similar finding on educational readability for multimedia precisely for font size and video [45]. By readability, we mean that the way a text, an image, or a video is graphically displayed (formatting) should make it simpler for people to read and comprehend. A legible interface is a must-have feature of every digital product mentioned. Text, videos, and graphics in educational games must fulfil specific formatting requirements [46]. Furthermore, a significant feature would be the layout of the content on the screen, which must provide ease of reading and seeing. The text in their research of the "Live Well, Live Healthy!" game was left-justified, and the sole font utilised is Arial (12 pts for regular text and 14 pts for headings). As a result, this font size will be the most widely used on the web in the future, as it gives the best readability to users. Nonetheless, 
storyboard generation is an important criterion in the construction of game scenarios for the level and inclusion of planning for the portrayal of the different game elements through a flow chart [47]. As a result, a narrative board was created to guarantee that the design and development process was more structured and systematic.

Figueroa has also highlighted some of these elements, also referred to as components, that can be found in most games nowadays, such as points, badges, leader boards, progress bars/progression charts, performance graphs, missions, levels, avatars, social elements, and prizes [20]. All of these elements serve distinct functions and may be used in virtually any job, company, or educational setting. As with this study, points, progress bars, performance graphs, quests/activities, levels, avatars, incentives, reporting, and certification were the agreed-upon features to be included in the design and implementation of the online gamified learning that corresponded to Figueroa's statements. Khaleel also conducted a similar study to discuss the derivation of game elements that will induce positive effects when applied to a learning application, and has stated that within the learning environment, the benefits of gamification elements cannot be ignored, because the main goal is to increase students' engagement, motivation, and understanding using a fun and enjoyable environment. Such components being used in gamification is a critical strategy of much software because, when fitted into any application, this technique may assist in the achievement of favourable results [48].

Effective, engaging learning and teaching approaches are totally vital. The primary issue in education is learners' behavioural desire to use online learning [49]. Adhering to this, Figueroa has stated that any game aspect utilised in gamification automatically increases the teaching and learning process, which in this case would be the language competency. In the use of points, which was authorised as part of the design and development of online gamified learning, the points system was found to produce the "surprise and delight" element, which helped to engage the learners [20,50].

In terms of the domination of the primary categories of game features, Figueroa emphasised that it is typical to include a leader board, progress bar, and performance graph, which may act as a powerful incentive. This category is commonly used to encourage collaboration. Prizes or awards are another type of reward system. This sort of reward appears in games where the player may unlock more activities or levels after completing the previous ones satisfactorily [20]. Prizes/awards inspire more dedication and involvement on the part of the player, which is one feature that persists in the learning of a language as well. Finally, achievements are shown as symbols in the player's online profile [20].

Most importantly for the level is to ensure that the player is aware of how far he or she has advanced in the level. Furthermore, it provides the player with information on the goals that have been achieved as well as the activities that must be completed in order to finish the level. It also reflects the player's journey, which may consist of a succession of little difficulties nested inside a harder hurdle [20]. This promotes growth by systematically encouraging healthy competition and displaying the progress to the other participants. They may then observe his or her development and become risk takers who are driven to move on and continue.

The gamification of online learning has made a big contribution to the simplification of the traditional techniques of learning [31]. Teachers regard the work at hand as less critical, and its accomplishment as more gratifying, when using online gamified learning [51]. The agreed-upon suggestions were considered based on the needs of and appropriateness to the target group that will use the online gamified learning using Classcraft to enhance the teachers' professional competencies. This consideration is in line with the recommendations of scholars, which was taken into account in the appropriate elements for targeted gamers [52]. In a nutshell, the online gamified learning module designed and developed on Classcraft eventually helped the teachers to uplift their competency from B2 to a minimum of $\mathrm{C} 1$, which was the evident final outcome of the complete research, as this study is based on the English language teachers' achievement in enhancing their professional competencies by mastering the knowledge and skills mentioned earlier. According to Freeman, a 
teacher's "command of English" is generally characterized as enhancing overall English competence, their language capability for enhanced teaching in classroom, and then the students' learning. This implies that teachers' language competency in the classroom is assessed both interactively and contextually [53].

Therefore, online gamified learning has, by now, established a significant existence in a versatile manner not only in education but in many varied fields [54-56]. Education is, and has always been, one of the most knowledge-intensive sectors. Generations have grown up playing online games, so it may seem inevitable that education was among the first to adopt them. The gamified environment may be an intriguing expectation because it is thought to foster social connectedness [57]. Scrutinising the core of gamified learning reveals that it is not a complete surprise; it has been utilised effectively in the business and education worlds [58]. With the advent of technological innovations across the world, online gamified learning has expanded in its use, which has resulted in a paradigm shift in language learning. Learners are given many opportunities to become deeply involved in their learning process [4]. It has become the order of the day for instructors to teach their students in universities. All of these are possible because the education system has undergone vast changes due to technology. Today, the education world has stepped into the technological realm, whereby the use of innovative technology makes learners become more engaged and motivated; they fully embrace it at the social and academic level [59]. Online games, in particular, employ game features and game design approaches to empower and engage learners with the motivation of skills for a learning approach and a continuous, comfortable environment. It has also been found to solidify the teaching and learning experience in the twenty-first century by motivating learners to learn as a result of the good outcomes achieved from the game. This is unquestionably consistent with the experts' recommended and agreed-upon-upon elements. Learning is defined as "working toward mastery of new understandings" via engagement and involvement in new learning activities, as well as the execution of new tasks and functions [60].

\section{Limitations and Future Directions}

Although the study has revealed some interesting insights into online gamified learning, some limitations should be kept in mind. The prominent highlight would be the limited literature available in relation to the combination of the study, whereby publications were only available in isolation for gamification and language studies-more precisely, English language-separately [24]. Apart from that, the study was only conducted on selected teachers at a smaller scale. Presumably, future research should address these issues and conduct more research in the field of gamification for Malaysian English language teachers under more stringent conditions and with a larger sample size in order to provide scholars with robust findings that can also be generalised to other learning situations [61]. On the other hand, there were few studies on the typical affordances and impediments that are present in online gamified learning settings. Online gamified learning environments generally provide learners with a variety of affordances that may be utilised in conjunction with ICT technologies [61]. There are obstacles and drawbacks to the use of online gamified learning, just as there are with any new educational tool. For example, when participating in an online gamified learning environment, technical affordances such as Internet disconnections might act as a counterpoint [62]. This has affected the duration and the speed of the completion of the quests in Classcraft. Some teachers were able to complete them faster than the other teachers because connectivity was an impediment to their finishing as intended. More study is likely required to shed light on the potential affordances and drawbacks that are inherent in the usage of gamification. The effects of online addictions such as digital and game addictions should also be looked at carefully, to investigate whether learning is promoted while avoiding addictions to online games $[63,64]$.

In assuring the susceptibility of the issue in demanding a quality teacher of professional competence, the The Ministry of Education might have contemplated recertifying English teachers' English proficiency. This would have been a realistic method of maintain- 
ing the highest level of quality among Malaysian English educators, as well as instilling in them a feeling of purpose, commitment, and duty to provide nothing but the best for Malaysia's young learners [37,64]. In the context of gamification, online gamified learning could possibly be an ephemera [63]. The moment they end, at the point of completion, the sustainability of the enhancement ceases to exist over the time. Nevertheless, the positive repercussions entail the success of this study as discussed.

More empirical study is needed in future to investigate the potentials of gamification. Longitudinal research, in addition to the implementation of full gamification features to evaluate its effects, are required in order to obtain a complete knowledge of the influence of gamification on learner engagement and motivation. There is a need to investigate the most effective game features that can foster the development of intrinsic motivation.

\section{Conclusions}

This study has added value in the expansion of and contribution to the literature in several aspects, namely English language, professional competencies, gamification and instructional technology. As the study has revealed, the agreed-upon elements are appropriate in the design of the online gamified learning. The agreed-upon elements nested in the content crafted in the development phase in Classcraft, with the aid of several features like objectives, content, gamification and skills, aided the English language teachers in enhancing their professional competency. Employing the ADDIE model as a parameter has upskilled and assisted the teachers in improving themselves accordingly. It has been dynamic in the development of a tool for the research being utilized in an online gamified learning platform. When learners use this platform, it was expected to give a complete picture of the learning process of the learners. Evidently, it has provided a vivid and structured basic pathway in designing and developing an online gamified learning platform not only to enhance teachers' competencies but also to empower the teachers to attempt the innovation with their students.

To sum up, between the zealots in support of the full gamification of the curriculum and the educational system, and the opponents who think online gamified learning is a distraction from the learning objectives, there remains a need for the further exploration of the full impact of gamification on engagement and motivation [61]. As such, a continuum for more in-depth study is proposed.

Author Contributions: All of the authors contributed to several aspects of the study. Conceptualization, S.D.K., H.N. and M.M.Y.; methodology, H.N. and M.M.Y.; validation, S.D.K., H.N. and M.M.Y.; formal analysis, S.D.K.; investigation, S.D.K.; resources, H.N. and M.M.Y.; data curation, S.D.K., H.N. and M.M.Y.; writing—original draft preparation, H.N.; writing—review and editing, S.D.K., H.N. and M.M.Y.; supervision, H.N. and M.M.Y.; project administration, S.D.K. and H.N.; funding acquisition, H.N. All authors have read and agreed to the published version of the manuscript.

Funding: This research was funded by MALAYSIA RESEARCH UNIVERSITIES NETWORK, grant number MRUN-RAKAN RU-2019-003/2, and UNIVERSITI KEBANGSAAN MALAYSIA, grant number GG-2021-012.

Institutional Review Board Statement: Not applicable.

Informed Consent Statement: Informed consent was obtained from all subjects involved in the study.

Data Availability Statement: Not applicable.

Acknowledgments: We would like to thank Malaysia Research Universities Network and Universiti Kebangsaan Malaysia for funding the work. We would also like to thank the participants of this research.

Conflicts of Interest: The authors declare no conflict of interest. 


\section{References}

1. Kaarakainen, M.-T.; Kivinen, A.; Kaarakainen, S.-S. Differences Between the Genders in ICT Skills for Finnish Upper Comprehensive School Students: Does Gender Matter? Seminar 2017, 13, 2.

2. Forsberg, J.-P. Gamification in Education-Utilization in Teaching of Languages. Bachelor's Thesis, Aalto University, Espoo, Finland, 2018; pp. 1-21.

3. Pramela, K.; Supyan, H. Online Forum and Language Learning Pedagogical Consideration; Universiti Putra Malaysia Press: Serdang, Malaysia, 2015.

4. Dewie, S.; Norman, H.; Yunus, M.M. Exploring the learning analytics of teachers in online learning. Int. J. Innov. Creat. Chang. 2019, 7, 40-53.

5. Malaysia Education Blueprint 2013-2025; Ministry of Education Malaysia: Putrajaya, Malaysia, 2013.

6. Norman, H.; Din, R.; Nordin, N. A Preliminary Study of an Authentic Ubiquitous Learning Environment for Higher Education. Recent Res. E-Act. Malays 2012, 3, 89-94.

7. The Roadmap 2015-2025; Ministry of Education Malaysia: Putrajaya, Malaysia, 2015.

8. Lynch, M. 8 Must Have Gamification Apps, Tools, and Resources. Available online: https:/ /www.theedadvocate.org/ 8-mustgamification-apps-tools-resources/ (accessed on 30 June 2021).

9. Major, C.H. Teaching Online: A Guide to Theory, Research, and Practice; Johns Hopkins University Press: Baltimore, MD, USA, 2015.

10. Boettcher, J.V.; Conrad, R.-M.; McQuesten, P. The Online Teaching Survival Guide: Simple and Practical Pedagogical Tips; Jossey-Bass: San Francisco, CA, USA, 2021.

11. Yunus, M.M.; Hashim, H.; Embi, M.A.; Lubis, M.A. The Utilization of ICT in the Teaching and Learning of English: 'Tell Me More'. Procedia-Soc. Behav. Sci. 2010, 9, 685-691. [CrossRef]

12. Dabbagh, N. The online learner: Characteristics and Pedagogical Implications. Contemp. Issues Technol. Teach. Educ. 2007, 7, 217-226.

13. Stavredes, T. Effective Online Teaching: Foundatins and Strategies for Student Success; Jossey-Bass: San Francisco, CA, USA, 2011.

14. Yunus, M.M. Innovation in Education And Language Learning In 21st Century. J. Sustain. Dev. Educ. Res. 2018, 2, 33. [CrossRef]

15. Budhai, S.S.; Skipwith, K.B. Best Practice in Engaging Online Learners through Active and Experiential Learning Strategies; Routledge: New York, NY, USA, 2017.

16. Lindsay, J. Connecting beyond the Classroom-Move from local to global learning modes. Scan 2017, 36, 27-38.

17. Blitz, C. Can Online Communities Achieve the Goals of Traditional Professional Learning Communities? What the Literature Says; Centre for Effective School Practices Institute of Education Sciences: Washington, DC, USA; National Center for Education Evaluation and Regional Assistance: Washington, DC, USA; Regional Educational Laboratory Mid-Atlantic: Washington, DC, USA, 2013.

18. Beveridge, L.; Stevens, R. Teachers as Researchers and Practitioners. Aust. Educ. Lead. 2020, 42, 37-43.

19. Executive Summary: Cambridge Evalution Study 2017; Ministry of Education Malaysia; Cambridge English Language Assessment: Cambridge, UK, 2017.

20. Figueroa-Flores, J.F. Gamification and Game-Based Learning: Two Strategies for the 21st Century Learner. World J. Educ. Res. 2016, 3, 507. [CrossRef]

21. Al-Azawi, R.; Al-Faliti, F.; Al-Blushi, M. Educational Gamification Vs. Game Based Learning: Comparative Study. Int. J. Innov. Manag. Technol. 2016, 7, 131-136. [CrossRef]

22. Malmberg, E. A Study on Gamification and Feedback Use by English Teachers in Swedish Upper Secondary School. Master's Thesis, Dalarna University, Falun, Sweden, 2018; pp. 1-7.

23. Kiryakova, G.; Angelova, N.; Yordanova, L. Gamification in education. In Proceedings of the 9th International Balkan Education and Science Conference, Edirne, Turkey, October 2014; Available online: https:/ /d1wqtxts1xzle7.cloudfront.net/ 53993983/293-Kiryakova-with-cover-page-v2.pdf?Expires=1632900638\&Signature=CIkj-TkkSJhD2ITTrQ1 \{\}HNb4cSkO7sg8 VD1Y84WgEY6G6Y3tXuVNgFppR7mhI5xnRY0pkZdQh \{\}KBB-Q1cpUNwY683ZHDaK76Om7sua4Kj5i5wab430r0b-E9za550 tjJE0NMjHQBhe3oIfMR9uJV7oVFqHzuvLZB8DcLyZ230FlJ9fJqFd9RiYLCUUdPcyYmMyymJDtpi407dSzWkyp2i2Bzgs7zn5 tDfVDL9 \{\}9Rnn2cpi0RVzgHL \{\}Wzh-LQqhm7jx8hCnvo9LO \{\}-rcNwDeclYoP7wcT0YYcxPEISLHrsEcEb3fTpy6njAkoE7 YLhzzCygQJtnvKx7aDvC2yNZZWpA_\&Key-Pair-Id=APKAJLOHF5GGSLRBV4ZA (accessed on 25 October 2020).

24. Kapp, K.M. The Gamification of Learning and Instruction: Game-Based Methods and Strategies for Training and Education; Pfeiffer: San Francisco, CA, USA, 2012.

25. Christians, G. The Origins and Future of Gamification; University of South Carolina: Columbia, SC, USA, 2018 ; pp. 3-43.

26. EdTech Innovation Showcase. Available online: https://www.classcraft.com/press/edtech-innovation-showcase/ (accessed on 25 October 2020).

27. Papadakis, S.; Kalogiannakis, M.; Orfanakis, V.; Zaranis, N. Novice Programming Environments. Scratch \& App Inventor. In Proceedings of the 2014 Workshop on Interaction Design in Educational Environments-IDEE '14, Albacete, Spain, 9 June 2014; pp. 1-7.

28. Positive Behaviors: Experience Points, Gold Pieces, and Levelling Up. Available online: https://help.classcraft.com/hc/en-us/ articles /360003425213-Positive-behaviors-Experience-Points-Gold-Pieces-and-leveling-up\#: \{\}:text=Experience $\% 20$ Points $\%$ 20(XP)\%20are\%20part,learning\%20journey\%20and\%20life \%20experience (accessed on 30 September 2020). 
29. Haris, D.A.; Sugito, E. Analysis of Factors Affecting User Acceptance of the Implementation of ClassCraft E-Learning: Case Studies Faculty of Information Technology of Tarumanagara University. In Proceedings of the 2015 International Conference on Advanced Computer Science and Information Systems (ICACSIS), Depok, Indonesia, 10-11 October 2015.

30. Sant, C. Leveling Up. Evaluating Theoretical Underpinnings and Applications of Gamification in the Classroom. Vanderbilt Uni-versity. Peabody College of Education and Human Development. 2014, pp. 16-19. Available online: https://ir.vanderbilt. edu/handle/1803/7109 (accessed on 25 October 2020).

31. Sanchez, E.; Young, S.; Jouneau-Sion, C. Classcraft: From Gamification to Ludicization of Classroom Management. Educ. Inf. Technol. 2016, 22, 497-513. [CrossRef]

32. Rivera-Trigueros, I.; del Sánchez-Pérez, M. Classcraft as a Resource to Implement Gamification in English-Medium Instruction. Teach. Train. Engl. -Medium Instr. High. Educ. 2020, 1, 356-371.

33. Kalogiannakis, M.; Papadakis, S. Evaluating the Effectiveness of a Game-Based Learning Approach in Modifying Students' Behavioural Outcomes and Competence, in an Introductory Programming Course. A Case Study in Greece. Int. J. Teach. Case Stud. 2019, 10, 235. [CrossRef]

34. Clarke, S.; Arnab, S.; Morini, L.; Heywood, L. Dungeons and Dragons as a Tool for Developing Student Self-reflection Skills. In Proceedings of the Games and Learning Alliance: 7th International Conference, GALA 2018, Palermo, Italy, 5-7 December 2018.

35. Kelly, T. Why Does “Just Add Gameplay" Endure? Available online: https://techcrunch.com/2014/06/01/just-add-gameplay/ (accessed on 27 September 2020).

36. Milyakina, S. Classcraft: Semiotic Analysis of Educational Role-Playing Game. Available online: https://www.academia.edu/30 087014/Classcraft_Semiotic_Analysis_of_Educational_Role_Playing_Game (accessed on 30 September 2020).

37. Sukri, S.I.A.; Yunus, M.M. Delving into the contents of the Pro-ELT programme. Int. J. Engl. Educ. 2018, 7, $234-247$.

38. Apriliyanti, D. English Teachers' Competences on PLPG (An Evaluative Study Based on Kirkpatricks' Model); Fakultas Ilmu Tarbiyah Dan Keguruan UIN Syarif Hidayatullah: Jakarta, Indonesia, 2018.

39. Malaysian Teacher Standards; Teacher Education Division: Putrajaya, Malaysia, 2009.

40. Richey, R.C.; Klein, J.D. Design and Development Research. In Handbook of Research on Educational Communications and Technology; Spinger: New York, NY, USA, 2013; pp. 141-150.

41. Richey, R.C.; Klein, J.D.; Nelson, W.A. Developmental Research: Studies of Instructional Design and Development. In Handbook of Research on Educational Communications and Technology; Jonassen, D.H., Ed.; Lawrence Erlbaum Associates: Mahwah, NJ, USA, 2014; pp. 1099-1130.

42. ELTC Report; Ministry of Education Malaysia, English Language Teaching Centre: Bandar Enstek, Malaysia, 2018.

43. Gunter, G.A.; Kenny, R.F.; Vick, E.H. Taking Educational Games Seriously: Using the RETAIN Model to Design Endogenous Fantasy into Standalone Educational Games. Educ. Technol. Res. Dev. 2007, 56, 511-537. [CrossRef]

44. Ahmad, T.S.; Hussin, A.A. Application of the Bloom's Taxonomy in Online Instructional Games. Int. J. Acad. Res. Bus. Soc. Sci. 2017, 7, 1009-1020.

45. Sauvé, L.; Renaud, L.; Kaufman, D.; Duplàa, E. Validation of the Educational Game for Seniors: “Live Well, Live Healthy!". Procedia -Soc. Behav. Sci. 2015, 176, 674-682. [CrossRef]

46. Pavithra, A. Multimedia and Its Applications. Int. J. Res. Dev. Technol. 2018, 10, 2349-3585.

47. Aleem, S.; Capretz, L.F.; Ahmed, F. Game Development Software Engineering Process Life Cycle: A Systematic Review. J. Softw. Eng. Res. Dev. 2016, 4, 6. [CrossRef]

48. Khaleel, F.L.; Sahari@Ashaari, N.; Tengku Wook, T.S.; Ismail, A. Gamification Elements for Learning Applications. Int. J. Adv. Sci. Eng. Inf. Technol. 2016, 6, 868. [CrossRef]

49. Yunus, M.M.; Ang, W.S.; Hashim, H. Factors Affecting Teaching English as a Second Language (TESL) Postgraduate Students' Behavioural Intention for Online Learning during the COVID-19 Pandemic. Sustainability 2021, 13, 3524. [CrossRef]

50. Seaborn, K.; Fels, D.I. Gamification in Theory and Action: A Survey. Int. J. Hum. -Comput. Stud. 2015, 74, 14-31. [CrossRef]

51. Pesek, M.; Suhadolnik, L.; Šavli, P.; Marolt, M. Motivating Students for Ear-Training with a Rhythmic Dictation Application. Appl. Sci. 2020, 10, 6781. [CrossRef]

52. Hamari, J.; Shernoff, D.J.; Rowe, E.; Coller, B.; Asbell-Clarke, J.; Edwards, T. Challenging Games Help Students Learn: An Empirical Study on Engagement, Flow and Immersion in Game-Based Learning. Comput. Hum. Behav. 2016, 54, 170-179. [CrossRef]

53. Freeman, D.; Katz, A.; Garcia Gomez, P.; Burns, A. English-for-Teaching: Rethinking Teacher Proficiency in the Classroom. ELT J. 2015, 69, 129-139. [CrossRef]

54. Mahmud, S.N.; Husnin, H.; Tuan Soh, T.M. Teaching Presence in Online Gamified Education for Sustainability Learning. Sustainability 2020, 12, 3801. [CrossRef]

55. Antonaci, A.; Klemke, R.; Specht, M. The Effects of Gamification in Online Learning Environments: A Systematic Literature Review. Informatics 2019, 6, 32. [CrossRef]

56. Nieto-Escamez, F.A.; Roldán-Tapia, M.D. Gamification as Online Teaching Strategy During COVID-19: A Mini-Review. Front. Psychol. 2021, 12, 648552. [CrossRef] [PubMed]

57. Shpakova, A.; Dörfler, V.; MacBryde, J. Changing the Game: A Case for Gamifying Knowledge Management. World J. Sci. Technol. Sustain. Dev. 2017, 14, 143-154. [CrossRef] 
58. Boyinbode, O. Development of a Gamification Based English Vocabulary.Mobile Learning System. Int. J. Comput. Sci. Mob. Comput. 2018, 7, 183-191.

59. Alabbasi, D. Exploring Graduate Students' Perspectives towards Using Gamification Techniques in Online Learning. Turk. Online J. Educ. Technol. 2018, 17, 34-45. [CrossRef]

60. Norman, H.; Nordin, N.; Din, R.; Ally, M.; Dogan, H. Exploring the Roles of Social Participation in Mobile Social Media Learning: A Social Network Analysis. Int. Rev. Res. Open Distrib. Learn. 2015, 16, 205-224. [CrossRef]

61. Dehghanzadeh, H.; Fardanesh, H.; Hatami, J.; Talaee, E.; Noroozi, O. Using Gamification to Support Learning English as a Second Language: A Systematic Review. Comput. Assist. Lang. Learn. 2019, 2019, 1648298. [CrossRef]

62. Guaqueta, C.A.; Castro-Garces, A.Y. The Use of Language Learning Apps as a Didactic Tool for EFL Vocabulary Building. Engl. Lang. Teach. 2018, 11, 61. [CrossRef]

63. Dichev, C.; Dicheva, D. Gamifying Education: What Is Known, What Is Believed and What Remains Uncertain: A Critical Review. Int. J. Educ. Technol. High. Educ. 2017, 14, 9. [CrossRef]

64. Dogan, H.; Norman, H.; Alrobai, A.; Jiang, N.; Nordin, N.; Adnan, A. A web-based intervention for social media addiction disorder management in higher education: Quantitative survey study. J. Med. Internet Res. 2019, 21, e14834. [CrossRef] [PubMed] 